\title{
Effects of Concentrated Ambient Particles on Heart Rate, Blood Pressure, and Cardiac Contractility in Spontaneously Hypertensive Rats
}

\author{
Chuen-Chau Chang \\ Institute of Occupational Medicine and Industrial Hygiene, National Taiwan University, Taipei, and \\ Department of Anesthesiology, China Medical College Hospital, Taichung, Taiwan
}

\author{
Jing-Shiang Hwang \\ Institute of Statistical Science, Academia Sinica, Taipei, Taiwan
}

Chang-Chuan Chan

Institute of Occupational Medicine and Industrial Hygiene, National Taiwan University, Taipei, Taiwan

\author{
Peng-Yau Wang \\ Graduate Institute of Environmental Engineering, National Central University, Chung-Li, Taiwan
}

\section{Tsuey-Hwa Hu}

Institute of Statistical Science, Academia Sinica, Taipei, Taiwan

\section{Tsun-Jen Cheng}

Institute of Occupational Medicine and Industrial Hygiene, National Taiwan University, Taipei, Taiwan

\begin{abstract}
Epidemiological studies have shown that particulate matter (PM) air pollution is associated with cardiovascular mortality and morbidity, especially for particles with aerodynamic diameters under $2.5 \mu \mathrm{m}\left(\mathbf{P M}_{2.5}\right)$. Recent studies have revealed an association between PM pollution and autonomic functions including heart rate (HR), blood pressure (BP), and heart-rate variability. However, the association and linking mechanisms have not been clearly demonstrated in animal studies. Utilizing a novel approach that employs a mixed-effects model to overcome the problems of variations in diseased animals and circadian cycles, we have previously demonstrated an association between concentrated $\mathrm{PM}_{2.5}$ and changes of $\mathrm{HR}$ and $\mathrm{BP}$ in pulmonary hypertensive rats. The objective of this study is to test the plausibility of this methodology and to demonstrate the particle effects under different pathophysiology. The feasibility of cardiac contractility (measured as QA interval, QAI) as an indicator for PM toxicology was also explored. Four spontaneously hypertensive (SH) rats were repeatedly exposed to concentrated $\mathrm{PM}_{2.5}$ during spring and summer. The mass concentration of particles during the $5 \mathrm{~h}$ of exposure was 202.0 \pm 68.8 (mean $\pm \mathrm{SE}$ ) and 141.0 $\pm 54.9 \mu \mathrm{g} / \mathrm{m}^{3}$ for spring and summer experiments, respectively. During spring exposures, the maximum increase of $\mathrm{HR}$ and mean BP noted at the end of exposure were $51.6 \mathrm{bpm}(p<.001)$ and $8.7 \mathrm{~mm} \mathrm{Hg}(p=.002)$, respectively. The maximum decrease of QAI noted at the same time was $1.6 \mathrm{~ms}(p=.001)$. Though a similar pattern was demonstrated during summer exposures, the responses were less prominent. We conclude that concentrated $\mathrm{PM}_{2.5}$ may increase $\mathrm{HR}$ and mean BP and decrease QAI in SH rats. Our results also show that QAI may be used as an indicator in PM toxicology.
\end{abstract}

Received 11 June 2003; sent for revision 26 June 2003; accepted 9 July 2003.

The authors are grateful to Ming-Chih Chen and Yu-Chen Lei for their technical assistance. The authors also thank the National Institute of Environmental Analysis, EPA, Taiwan, for its administrative support (funded by EPA-91-FA11-03-91DF02).

Address correspondence to Dr. T.-J. Cheng, Institute of Occupational Medicine and Industrial Hygiene, College of Public Health, National Taiwan University, 1 Jen-Ai Rd. Sec. 1, Taipei, Taiwan 100. E-mail: tcheng@ ha.mc.ntu.edu.tw 
Increased concentrations of ambient particles are associated with cardiovascular morbidity and mortality in many epidemiological studies (Pope \& Dockery, 1999; Samet et al., 2000). Research has also indicated that particles with aerodynamic diameter less than $2.5 \mu \mathrm{m}\left(\mathrm{PM}_{2.5}\right)$ exert greater adverse health effects than coarse particles (Pope et al., 1995). However, the mechanisms of such associations have not yet been clearly defined. Recent epidemiological studies have found associations of increased air particles with increased heart rate, blood pressure, and arrhythmia, and with decreased heart rate variability (Peters et al., 1999, 2000; Pope et al., 1999; Gold et al., 2000; Ibald-Mulli et al., 2001). Activation of autonomic nervous system (ANS) has been postulated to play a role in these relationships (Stone \& Godleski, 1999). To further clarify these relationships, animal models have been used to investigate the effects of particles on heart rate and blood pressure (Godleski et al., 1996; Kodavanti et al., 1998). Results of the preliminary studies, however, were inconsistent (Godleski et al., 1996; Watkinson et al., 1998, 2001). This is probably due to the inadequacy of the experimental designs. Because of the wide variation among diseased animals and circadian cycle of hemodynamic parameters, a large number of animals is usually required to delineate the true effect of air particles (Kodavanti et al., 1998). To overcome this problem, we successfully used self-control design and a mixed-effects model to detect the effects of particles on heart rate and mean blood pressure (MBP) in three pulmonary hypertensive Sprague-Dawley (SD) rats exposed repeatedly and alternately to concentrated ambient particles (CAP) and filtered air (Cheng et al., 2003). In order to further clarify the plausibility of the methodology and the particle effects under different pathophysiology, we used a similar tactic to investigate the effect of concentrated $\mathrm{PM}_{2.5}$ on heart rate and MBP in spontaneously hypertensive $(\mathrm{SH})$ rats in this study. A recent study had observed exacerbated cardiopulmonary injury and oxidative stress in SH rats exposed to PM. The study concluded that $\mathrm{SH}$ rat is a potentially useful model with susceptibility to cardiovascular diseases (Kodavanti et al., 2000).

Cardiac contractility is under close modulation of ANS functioning (Kent \& Cooper, 1975; Kawano et al., 2003), and thus is likely to respond well to CAP exposures, since ANS responses have been postulated as an important mechanism linking CAP and cardiovascular toxicity. Using QA intervals (QAI) as an index of cardiac contractility, the feasibility of applying cardiac contractility to the PM toxicology was also explored in this study.

\section{MATERIAL AND METHODS}

\section{Animals and Development of Systemic Hypertension}

Sixty-day-old male SH rats were obtained from the National Laboratory Animal Breeding and Research Center in Taiwan. Housed individually in cages with Aspen chip bedding renewed twice weekly, the $\mathrm{SH}$ rats were provided with PmI/LabDiet
5001 and water ad libitum except during the PM exposure periods. A 12-h light/dark cycle, a constant room temperature of 22 $\pm 1{ }^{\circ} \mathrm{C}$, and a relative humidity of $55 \pm 10 \%$ were maintained in the animal room during the study. Owing to the genetic makeup of SH rats, a systolic pressure over $150 \mathrm{~mm} \mathrm{Hg}$ develops spontaneously by the age of $5 \mathrm{wk}$, and is maintained thereafter at higher levels (Okamoto et al., 1974).

\section{Experimental Design}

Four SH rats were implanted with radiotelemetry transmitters (model TL11M2-C50-PXT, Data Sciences International, St. Paul, MN) at the age of $10 \mathrm{wk}$. Two weeks for surgical recovery was allowed before baseline data collection. Baseline data consisting of ECG and aortic blood pressure signals were collected on unanesthetized, unrestrained animals, over a period of $1 \mathrm{wk}$ before CAP exposure in both the spring and summer.

Ambient particles in the Chung-Li area, a suburb of Taipei, were concentrated by a modified ultrafine particle concentrator (UFPC) (Sioutas et al., 1999). Ambient particles were carried by a major flow of $110 \mathrm{~L} / \mathrm{min}$ to a warm-water bath for oversaturation, and grown in a cooling condenser, selected by a virtual impactor, and recovered to their original aerodynamic diameters between 2.5 and $0.01 \mu \mathrm{m}$ by a diffusion dryer. The UFPC produced a negative pressure of around $2 \mathrm{~mm} \mathrm{Hg}$ inside the nose-only exposure chamber with an output minor flow of $10 \mathrm{~L} / \mathrm{min}$. A condensation particle counter (CPC, model 3022A, TSI, Shoreview, MN), located on both input and output arms, was used to analyze the particle concentrations before and after UFPC for every $30 \mathrm{~s}$. Placed in one of the two output arms, polycarbonate filter paper was used to collect the particles for mass concentration calculation.

Experiments were conducted on Tuesdays and Thursdays in the spring, and on Mondays and Thursdays in the summer. There were 4 days of exposure in the spring season, specifically, 26 and 28 February and 5 and 7 March 2002, and 6 days of exposure in the summer, namely, 6, 13, 17, 20, and 27 June and 4 July 2002.

On the days of the experiment, about $1 \mathrm{~h}$ of accommodation (10:00 to 11:00) in closed-type animal holders (model $\mathrm{CH}$ 2500, CH Technologies (USA), Westwood, NJ) was allowed before the animals were fitted to the connector cones of noseonly exposure system (12-port nose-only modular, $\mathrm{CH}$ Technologies) at 11:00. Two SH rats were then exposed to CAP (exposure group), while the other two were exposed to HEPA filtered air (control group) for $5 \mathrm{~h}$ (11:00 to 16:00). SH rats served as exposure and control group alternatively.

\section{Heart Rate, Blood Pressure, and Cardiac Contractility Measurements}

With the radiotelemetry system, all signals throughout the study were collected on a continuous basis. The sampling rates for the electrocardiograph (ECG) signals were set at 1000 points per second $(1000 \mathrm{~Hz})$ for better temporal discrimination, and $500 \mathrm{~Hz}$ for blood pressure signals. Parameters including 
electrocardiograph (ECG)-derived heart rate (HRE) and mean blood pressure (MBP) were retrieved from the system at 10-min intervals.

Cardiac contractility was measured by QA interval (QAI), which was defined as the time duration between the $\mathrm{Q}$ wave in the ECG panel and point A (pressure upstroke in aortic pressure) in the pressure panel, in units of milliseconds (ms). QAI was automatically calculated by the system, and the 10-min means were output as a parameter.

\section{Statistic Analysis}

Owing to low-power effects in the fourth SH rat during summer experiments, a decreasing trend of MBP data was observed for the last $3 \mathrm{wk}$ before signal transmission went out completely. Time duration data, including HRE and QAI, were not affected at the same time. The MBP data during summer experiments of the fourth $\mathrm{SH}$ rat were then excluded from statistic analysis.

The three measured parameters, HRE, MBP, and QAI, were classified into three groups by experimental conditions of exposure group (exposed to CAP), control group (exposed to filtered air while staying in nose-only exposure system), and baseline group (exposed to room air during baseline period). Each rat's circadian baselines in the two seasons were separately estimated using hourly means of measurements obtained from its baseline data. The circadian baselines were then subtracted from the HRE, MBP, and QAI data for the corresponding hours to obtain crude effects for each rat in the two seasons separately.

The average crude effects of all SH rats in baseline (dotted lines), control (dashed lines), and exposure (solid lines) groups plotted against clock hours are shown in Figure 1. The average crude effects for baseline group are around 0 , showing no circadian pattern. During the preparatory stage of 10:00 to 11:00, SH rats stayed in animal holders for accommodation, and the average crude effects in HRE and MBP for both control group and exposure group increased from the baseline condition owing to mild stress. At the same time, QAI decreased during this preparatory stage. The chamber effects, denoted by the crude effects of control group data, developed as the SH rats entered the animal holders, and gradually diminished to some extent through the course of the inhalation stage from 11:00
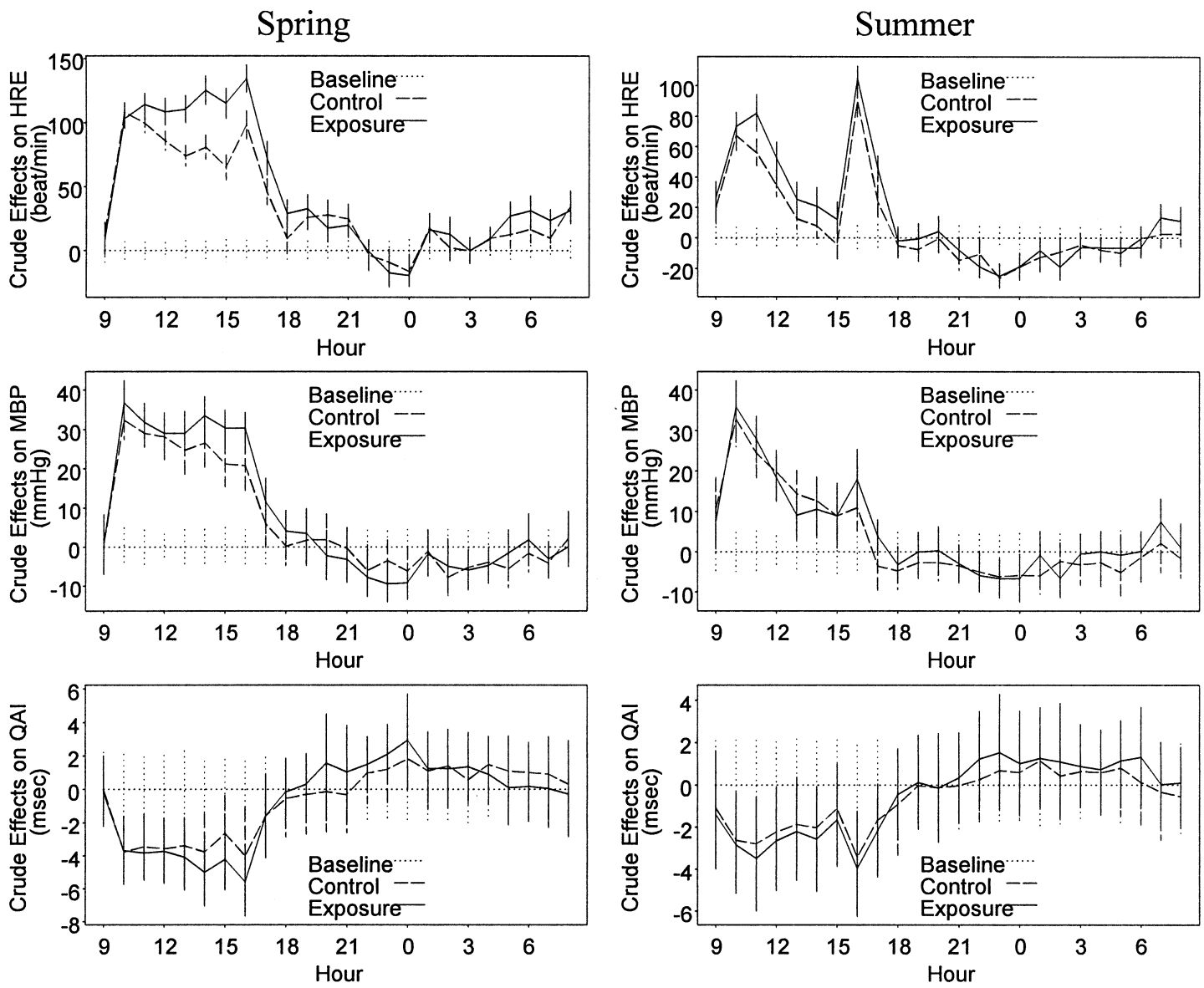

FIG. 1. The averages of crude effects across all SH rats plotted against clock hours. Spring data are shown in the left column, and summer in the right column. Data of HRE are in the upper panels, MBP in the middle, and QAI in the lower panels. Baseline group data are shown in dotted lines, control group in dashed lines, and exposure group in solid lines. 
Spring
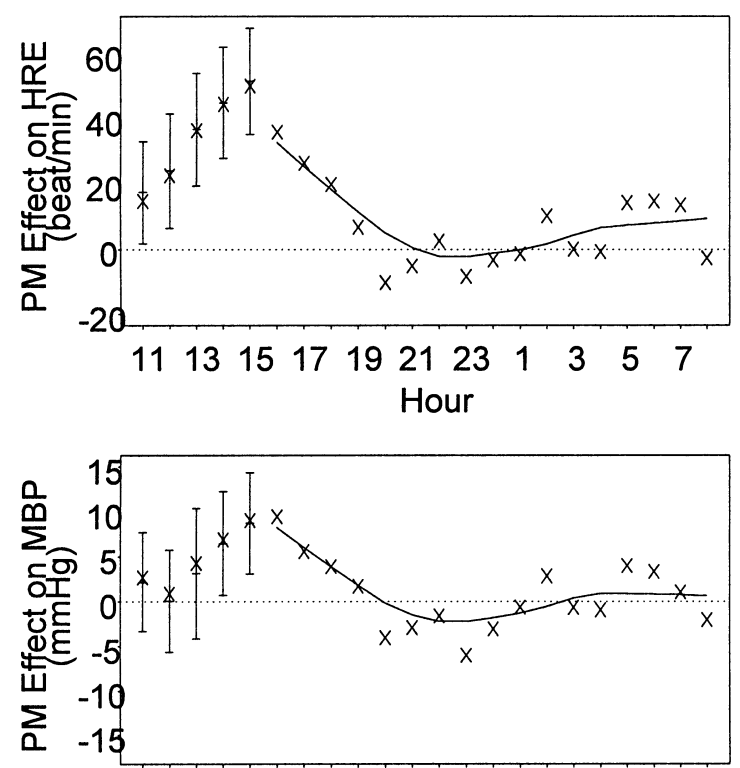

$\begin{array}{lllllllllll}11 & 13 & 15 & 17 & 19 & 21 & 23 & 1 & 3 & 5 & 7\end{array}$ Hour

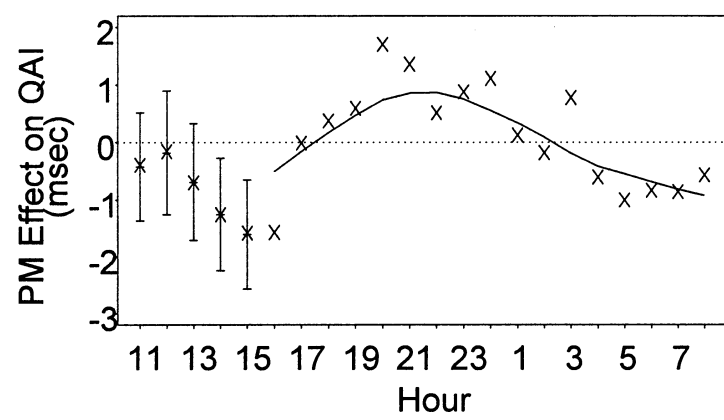

Summer
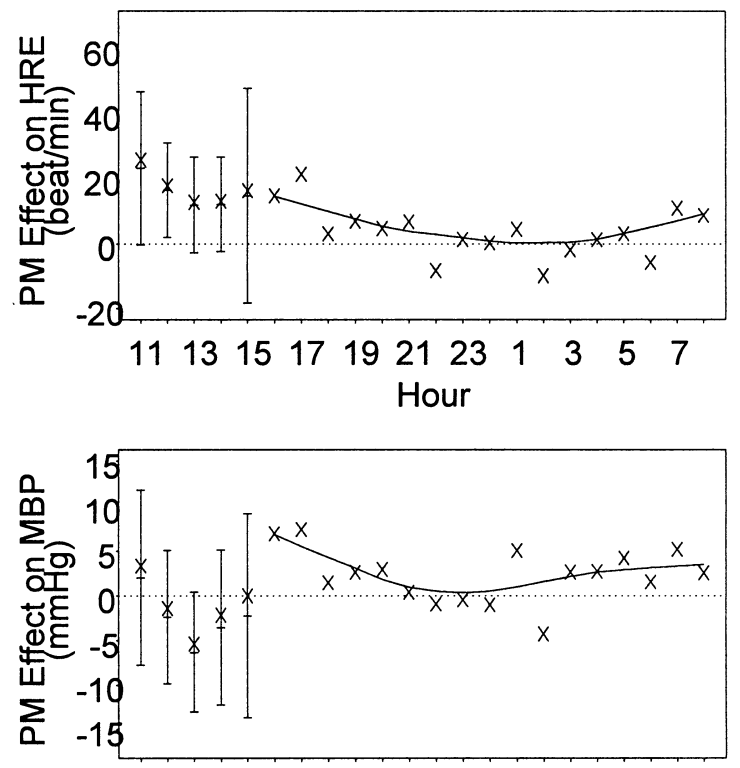

$\begin{array}{lllllllllll}11 & 13 & 15 & 17 & 19 & 21 & 23 & 1 & 3 & 5 & 7\end{array}$ Hour

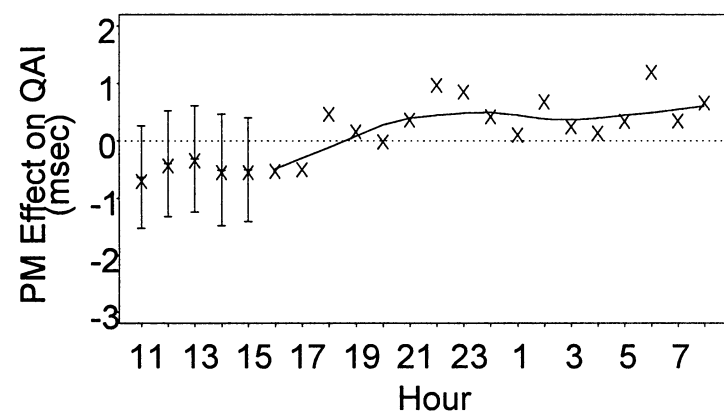

FIG. 2. Hourly means and estimates of PM effects. Spring data are shown in the left column, and summer in the right column. Data of HRE are in the upper panels, MBP in the middle, and QAI in the lower. The hourly means $(x)$ are smoothed by robust locally linear fits after exposures (smoothed curves after 16:00). The estimates (-) and 95\% confidence intervals of the PM effects during exposure (11:00 to 16:00) are obtained from mixed-effects models.

to $16: 00$. The chamber effects peaked at $16: 00$ as the animals were released from the nose-only exposure system and returned to baseline conditions within hours after the experiments (after 16:00). The differences between crude effects of exposure group and control group were defined as the PM crude effects. The average PM crude effects, as shown in Figure 2 by $\times$ symbols, evolved during the inhalation stage and also returned to the baseline condition after the end of the experiment.

We used a linear mixed-effects model to further examine the PM effect during exposure. Chamber effects and PM effects were both modeled with a set of dummy variables. There were 6 dummies for chamber effects and 5 for PM effects, each standing for 60-min estimation. Let $Y_{i k t}$ be the crude effect for the $i$ th $\mathrm{SH}$ rat in the $k$ th condition ( 0 for baseline group, 1 for control group, 2 for exposure group) at time $t$ ( 1 to 6 for each 60 -min section during the $6 \mathrm{~h}$ of the experiment). The mixed-effects model is given as

$$
\begin{aligned}
Y_{i k t}= & \sum_{m=1}^{6}\left(a_{m i}+\alpha_{m}\right) I\left(\mathrm{IN}_{i k m}\right) \\
& +\sum_{m=1}^{5}\left(b_{m i}+\beta_{m}\right) I\left(\mathrm{PM}_{i k(m+1)}\right)+\varepsilon_{i k t}
\end{aligned}
$$

where $I\left(\mathrm{IN}_{i k m}\right)=1$, when the $i$ th rat was in the chamber during the $k$ th experiment at the time $t=m(m=1-6)$ and 0 otherwise, $I\left(P M_{i k(m+1)}\right)=1$ when the $i$ th rat during the $k$ th experiment was receiving CAP at the time $t=m+1(m=1-5)$, and 0 otherwise. The error term $\varepsilon_{i k t}$ was chosen to be an autoregressive process with order 2 to model time dependence. The coefficients of $\alpha_{m}$, 
for $m=1$ to 6 , were used to describe the hourly mean fixed chamber effects during the $6 \mathrm{~h}$ of the experiment. The dummy variables $\beta_{m}$, for $m=2$ to 6 , were used to describe the 60 -min mean fixed PM effects during the $5 \mathrm{hr}$ of exposure. Since the four SH rats were randomly selected from a population, we added random components $a_{m i}$ and $b_{m i}$ to model the rat-to-rat variation of these effects. All these random coefficients were assumed to be normally distributed with the mean of 0 and some constant variances. We used S-Plus to estimate the parameters and standard errors of the estimates in the model.

\section{RESULTS}

Condensation particle counter (CPC) readings showed an average preconcentrating particle concentration of $1.59 \times 10^{4}$ (range: $5.28 \times 10^{3}$ to $5.08 \times 10^{4}$ ) particles $/ \mathrm{cm}^{3}$ and a postconcentrating level of $2.30 \times 10^{5}$ (range: $7.12 \times 10^{3}$ to $8.26 \times$ $10^{5}$ ) particles $/ \mathrm{cm}^{3}$, with an average concentrating power around 14 for the spring experiments. Concentrating power by CPC for summer exposures was around 17, with an average preconcentrating particle concentration of $1.59 \times 10^{4}$ (range: $2.90 \times 10^{3}$ to $1.21 \times 10^{5}$ ) particles $/ \mathrm{cm}^{3}$ and a postconcentrating level of $2.78 \times 10^{5}$ (range: $7.76 \times 10^{3}$ to $8.87 \times$ $10^{5}$ ) particles $/ \mathrm{cm}^{3}$. Gravimetric analysis revealed the postconcentrating mass concentration of particles during the $5 \mathrm{~h}$ of exposure of $202.0 \pm 68.8$ (mean $\pm \mathrm{SE}$ ) $\mu \mathrm{g} / \mathrm{m}^{3}$ for the spring experiments and $141.0 \pm 54.9 \mu \mathrm{g} / \mathrm{m}^{3}$ for the summer exposures.

The crude effects of HRE (upper panel), MBP (middle panel), and QAI (lower panel) are plotted against clock hours in Figure 1, with data from the spring experiments showing on the left-hand column and those from summer on the right. All the SH rats were fit into closed-type animal holders and accommodated from 10:00 to 11:00. The animals were mounted in the nose-only exposure system and started to receive CAP (for exposure group) or filtered air (for control group) at 11:00. As used for the baseline template, the crude effects of baseline group (dotted lines) oscillated around zero with no significant trend, justifying the appropriate removal of circadian trend. Effects of the control (dashed lines) and exposure (solid lines) groups evolved through the course of the experiment. During the preparatory manipulation from 10:00 to 11:00, the crude effects of HRE and MBP increased while that for QAI decreased owing to mild stress. Similar patterns of increased HRE and MBP, together with decreased QAI, were also observed during CAP exposure period. There were prominent differences between CAP and filtered air exposures for all three parameters.

Table 1 shows the results of fixed effects in linear mixedeffects modeling. As shown, significant $\alpha_{m}$, for $m=1$ to 6 , indicated that chambering the animals into holders would significantly increase HRE and MBP and decrease QAI. These chamber effects were most prominent initially, and diminished to some extent toward the end of experiments. After the adjustment of chamber effects, HRE significantly increased during CAP exposures in spring season, to a maximum increase of
$51.6 \mathrm{bpm}(p<.001)$ at the end of experiments. The CAPrelated increase of HRE was less prominent in summer exposures, however. The changes of MBP caused by CAP exposure were somewhat different between the two seasons. MBP increased to a maximum of $8.7 \mathrm{~mm} \mathrm{Hg}(p=.002)$ at the end of spring exposures, while the changes were not significant during the summer experiments. The linear mixed-effects modeling also demonstrated the potential for CAP to decrease the QAI through the exposure course, with a maximum decrease of $1.60 \mathrm{~ms}(p=.001)$ at the end of the spring exposures, but not significant decrease in summer experiments.

In Figure 2, the averaged observed PM effects on HRE (upper panel), MBP (middle panel), and QAI (lower panel) were plotted against clock hours (by symbols $\times$ ) with data from spring experiments showing on the left-hand column and those from summer on the right. The estimated PM effects, predicted from linear mixed-effects models (by symbols-for 11:00 to 16:00), together with 95\% confidence intervals (vertical bars for 11:00 to 16:00), showed increased HRE and MBP and decreased QAI in spring exposures. These CAP-related changes were less prominent in summer, however. The close approximation between observed $(\times)$ and estimated $(-)$ PM effects demonstrated the goodness of fit (GOF) of the mixed-effects models. The PM effects after exposures were smoothed by robust locally linear fits to delineate their course returning to the baseline (solid curves after 16:00).

\section{DISCUSSION}

In this study, we demonstrated that animals exposed to CAP had increased HRE and MBP and decreased QAI in experiments conducted in the spring. However, this trend was less prominent in the summer.

Epidemiological studies have shown that increased heart rate is associated with increased ambient PM (Pope et al., 1999; Peters et al., 1999). However, the relationship between heart rate and PM has been inconsistent in animal studies, depending on the experimental designs used. Decreased heart rate has been observed in animals exposed to tracheally instilled ROFA (Watkinson et al., 2001, 2003), and tracheally instilled PM (Kang et al., 2002). Furthermore, transition metals have been linked to this cardiovascular change of PM (Campen et al., 2001; Muggenburg et al., 2003). However, heart rate increase was observed in pulmonary hypertensive SD rats exposed to CAP (Gordon et al., 1998), though decreased heart rate was also observed on SH rats exposed to CAP (Nadziejko et al., 2002). Because of intersubject variability and changes of circadian cycles of heart rate, the results of previous studies have been inconsistent. Using repeated measurements of heart rate for each animal and a mixed-effects model analysis, we have previously demonstrated that CAP exposure could decrease HRE and MBP on SD rats with pulmonary hypertension (Cheng et al., 2003). Interestingly, we observed that CAP increased HRE on SH rats in the spring experiments, while the responses in the summer were less prominent. 
TABLE 1

Regression results of fixed effects on HRE, MBP, and QAI using a linear mixed-effects model

\begin{tabular}{|c|c|c|c|c|c|c|c|c|c|}
\hline \multirow[b]{2}{*}{ Season/coefficient } & \multicolumn{3}{|c|}{ HRE (bpm) } & \multicolumn{3}{|c|}{ MBP (mm Hg) } & \multicolumn{3}{|c|}{ QAI (ms) } \\
\hline & Value & SE & $p$ Value & Value & SE & $p$ Value & Value & SE & $P$ Value \\
\hline \multicolumn{10}{|l|}{ Spring } \\
\hline$\alpha_{1}$ & 109.2 & 6.0 & .000 & 36.0 & 2.7 & .000 & -3.76 & 0.24 & .000 \\
\hline$\alpha_{2}$ & 100.3 & 6.2 & .000 & 30.3 & 2.2 & .000 & -3.43 & 0.38 & .000 \\
\hline$\alpha_{3}$ & 86.4 & 6.4 & .000 & 29.1 & 2.2 & .000 & -3.56 & 0.37 & .000 \\
\hline$\alpha_{4}$ & 74.7 & 6.8 & .000 & 25.7 & 2.9 & .000 & -3.37 & 0.37 & .000 \\
\hline$\alpha_{5}$ & 81.0 & 7.1 & .000 & 27.3 & 2.2 & .000 & -3.73 & 0.37 & .000 \\
\hline$\alpha_{6}$ & 64.5 & 8.7 & .000 & 22.1 & 2.2 & .000 & -2.59 & 0.38 & .000 \\
\hline$\beta_{1}$ & 17.4 & 7.8 & .027 & 2.2 & 2.8 & .428 & -0.42 & 0.47 & .369 \\
\hline$\beta_{2}$ & 24.0 & 8.8 & .007 & 0.1 & 2.9 & .977 & -0.18 & 0.54 & .742 \\
\hline$\beta_{3}$ & 36.7 & 8.6 & .000 & 3.1 & 3.6 & .391 & -0.69 & 0.51 & .176 \\
\hline$\beta_{4}$ & 45.0 & 8.5 & .000 & 6.5 & 2.9 & .025 & -1.25 & 0.49 & .011 \\
\hline$\beta_{5}$ & 51.6 & 8.1 & .000 & 8.7 & 2.8 & .002 & -1.60 & 0.48 & .001 \\
\hline \multicolumn{10}{|l|}{ Summer } \\
\hline$\alpha_{1}$ & 68.7 & 7.7 & .000 & 33.5 & 2.3 & .000 & -2.72 & 0.26 & .000 \\
\hline$\alpha_{2}$ & 56.7 & 5.0 & .000 & 24.7 & 2.6 & .000 & -2.81 & 0.36 & .000 \\
\hline$\alpha_{3}$ & 34.9 & 5.2 & .000 & 20.0 & 2.4 & .000 & -2.23 & 0.50 & .000 \\
\hline$\alpha_{4}$ & 13.2 & 5.2 & .012 & 14.8 & 2.4 & .000 & -1.87 & 0.48 & .000 \\
\hline$\alpha_{5}$ & 8.5 & 5.2 & .103 & 13.3 & 2.4 & .000 & -2.04 & 0.35 & .000 \\
\hline$\alpha_{6}$ & -3.2 & 13.3 & .810 & 10.1 & 8.3 & .225 & -1.15 & 0.33 & .000 \\
\hline$\beta_{1}$ & 23.2 & 11.8 & .049 & 2.0 & 4.9 & .680 & -0.63 & 0.45 & .159 \\
\hline$\beta_{2}$ & 16.5 & 7.2 & .023 & -2.4 & 3.7 & .526 & -0.40 & 0.46 & .391 \\
\hline$\beta_{3}$ & 12.0 & 7.3 & .104 & -6.3 & 3.4 & .061 & -0.31 & 0.46 & .498 \\
\hline$\beta_{4}$ & 12.2 & 7.3 & .095 & -3.5 & 4.3 & .419 & -0.51 & 0.49 & .297 \\
\hline$\beta_{5}$ & 14.8 & 16.5 & .371 & -2.2 & 5.7 & .696 & -0.50 & 0.45 & .265 \\
\hline
\end{tabular}

Note. Hourly means of chambering effects were estimated by dummy variables $\alpha_{m}$, for $m=1$ to 6 corresponding to chamber stay from 10:00 to 16:00. Hourly means of PM effects were estimated by dummy variables $\beta_{m}$, for $m=1$ to 5 corresponding to exposure time from 11:00 to 16:00.

With similar experimental design and analysis, different HRE responses to CAP were observed. One explanation for the discrepancy in findings may be attributable to the variations in animal models. A study reported that ANS modulation over cardiovascular homeostasis was different between SD rats and SH rats (Sato et al., 2002). The hemodynamic responses to physiologic challenges were also found to be different between these two strains (McKeown \& Shoukas, 1998). The other explanation may come from variations in exposure domain. With experiments carried out in different periods of time, we speculated that PM composition and concentration might be different enough to cause dissimilar action on various airway sites that were known to elicit different cardiovascular responses (Widdicombe \& Lee, 2001).

Blood pressure responses to PM are less consistent and less prominent as compared to heart rate on human observations (Linn et al., 1999; Nightingale et al., 2000; Ibald-Mulli et al., 2001; Gong et al., 2003). Similarly, animal studies have been inconsistent (Toda et al., 2001; Vincent et al., 2001). In our previous study (Cheng et al., 2003), MBP decreased during CAP exposure on pulmonary hypertensive SD rats. In this research, however, we found that MBP increased with CAP in SH rats in the spring experiments, while the change was not significant in the summer. Similar explanations for heart rate may be attributable to the discrepancy in blood pressure.

Myocardium is under close modulation of ANS functioning to cope with daily and emergent incidences (Kent \& Cooper, 1975; Kawano et al., 2003). Since ANS has been proposed as one of the major mechanisms linking PM and cardiac events, we speculate that cardiac contractility may be sensitive to PM exposure and can be used as an effective indicator of PM toxicology. Various measurements have been used in the evaluation of cardiac contractility (Tibby \& Murdoch, 2003). QA interval (QAI), the time duration between the Q wave in the ECG and point $\mathrm{A}$ (the pressure upstroke) in aortograms, is sensitive in detecting changes in cardiac contractility, and independent of cardiac loading and heart rate. Owing to its simple calculation and specificity to changes in cardiac contractility, QAI has been used extensively in experimental and clinical settings (Cambridge \& Whiting, 1986). Recently, QAI has been used in 
pharmaceutical engineering as an index of cardiac stimulation by studied substances (Alabaster et al., 1988; Bell et al., 1989; Takahara et al., 2001). However, QAI has yet to be applied in the field of inhalation toxicology.

Cardiac contractility, heart rate, and wall tension had been listed as the three determinants of myocardial oxygen demand (Ruffolo \& Feuerstein, 1997). Increased cardiac contractility results in increased myocardial oxygen consumption (Cohn, 1998), and this may in turn be capable of inducing an imbalance between myocardial oxygen demand and supply, leading to ischemia in patients with coronary artery disease (van Rugge et al., 1992). CAP has been demonstrated in animal models to exacerbate myocardial ischemia in the face of acute occlusion of coronary arteries (Wellenius et al., 2003). In our current study, decreased QAI, or increased cardiac contractility, was noted during CAP exposures, though the responses in summer were less prominent. Thus, we postulate that QAI may be a sensitive and useful indicator in the study of PM-related cardiovascular toxicity.

The hemodynamic parameters used in the current study, including HRE, MBP, and QAI, responded less prominently in the summer observations. One explanation for this discrepancy is that CAP in the spring may have different components of PM from the summer. Further study with the characterization of CAP may shed light on the underlying mechanisms. The other explanation is a combination of aging process and hypertensive pathology of the SH rats. Aging has been associated with decreased cardiac contractility in both human studies (Harding et al., 1992) and animal models (Canepari et al., 1994). Molecular degeneration, including diminishing cardiac muscarinic receptor activity (Poller et al., 1997) and reduced sarcoplasmic calcium recycling (Kiriazis \& Gibbs, 2001), makes aging hearts less responsive to either pharmacologic stimulation (Canepari et al., 1994; Ferrara et al., 1995) or physiologic challenges (Fleg et al., 1994). Alternatively, systemic hypertension has also been linked to depressed cardiac contractility and thereby to inotropic responses to pharmacologic stimuli (Ren et al., 2000). Similarly, age-related blunting of hemodynamic responses, including heart rate, was also documented (Fleg et al., 1994).

Various types of receptors and neurons in mammalian airways have been associated with hemodynamic modulations. Rabbit upper airway and nostrils have been verified as sensitive areas linking cigarette smoke and cardiac contractility (Robleto $\&$ Peterson, 1981). Vagal pulmonary C fibers (Lai \& Kou, 1998) and olfactory bulb as a whole (Moffitt et al., 2002) have been demonstrated in anesthetized SD rats as an important afferent port and integral center for cardiovascular sympathoexcitatory reflexes. We speculate that CAP might influence the hemodynamic modulations via these pathways, and thereby link to its cardiovascular pathogenesis.

The relatively small sample size of our study prevents us from drawing a firm conclusion, although the study design and powerful linear mixed-effects model did show the significance of PM-related cardiac toxicity. Larger scale studies are still needed to verify the findings. We conclude that CAP may increase HRE and MBP and decrease QAI. The study also shows that QAI may be a sensitive and useful indicator in the study of PM-related cardiovascular toxicity.

\section{REFERENCES}

Alabaster, C. T., Bell, A. S., Campbell, S. F., Ellis, P., Henderson, C. G., Roberts, D. A., Ruddock, K. S., Samuels, G. M., and Stefaniak, M. H. 1988. 2(1H)-Quinolinones with cardiac stimulant activity. 1. Synthesis and biological activities of (six-membered heteroaryl)-substituted derivatives. J. Med. Chem. 31:20482056.

Bell, A. S., Campbell, S. F., Morris, D. S., Roberts, D. A., and Stefaniak, M. H. 1989. 2(1H)-Quinolinones with cardiac stimulant activity. 3. Synthesis and biological properties of 6-imidazol-1-yl derivatives. J. Med. Chem. 32:1552-1558.

Cambridge, D., and Whiting, M. V. 1986. Evaluation of the QA interval as an index of cardiac contractility in anesthetized dogs: Responses to changes in cardiac loading and heart rate. Cardiovasc. Res. 20:444-450.

Campen, M. J., Nolan, J. P., Schladweiler, M. C., Kodavanti, U. P., Evansky, P. A., Costa, D. L., and Watkinson, W. P. 2001. Cardiovascular and thermoregulatory effects of inhaled PM-associated transition metals: A potential interaction between nickel and vanadium sulfate. Toxicol. Sci. 64:243-252.

Canepari, M., Polla, B., Gualea, M. R., Zanardi, C., and Reggiani, C. 1994. Age-dependent reduction of the response of rat cardiac muscle to the phosphodiesterase inhibitor milrinone. Arch. Int. Physiol. Biochim. Biophys. 102:265-269.

Cheng, T. J., Hwang, J. S., Wang, P. Y., Tsai, C. F., Chen, C. Y., Lin, S. H., and Chan, C. C. 2003. Effects of concentrated ambient particles on heart rate and blood pressure in pulmonary hypertensive rats. Environ. Health Perspect. 11:147-150.

Cohn, P. F. 1998. Treatment of chronic myocardial ischemia: Rationale and treatment options. Cardiovasc. Drugs Ther. 12(suppl. 3):217223.

Ferrara, N., O’Gara, P., Wynne, D. G., Brown, L. A., del Monte, F., Poole-Wilson, P. A., and Harding, S. E. 1995. Decreased contractile responses to isoproterenol in isolated cardiac myocytes from aging guinea-pigs. J. Mol. Cell Cardiol. 27:1141-1150.

Fleg, J. L., Schulman, S., O'Connor, F., Becker, L. C., Gerstenblith, G., Clulow, J. F., Renlund, D. G., and Lakatta, E. G. 1994. Effects of acute beta-adrenergic receptor blockade on age-associated changes in cardiovascular performance during dynamic exercise. Circulation 90:2333-2341.

Godleski, J. J., Sioutas, C., Kalter, M., and Koutrakis, P. 1996. Death from inhalation of concentrated ambient particles in animal models of pulmonary diseases [abstract]. Am. J. Respir. Crit. Care Med. 153:A15.

Gold, D. R., Litonjua, A., Schwartz, J., Lovett, E., Larson, A., Nearing, B., Allen, G., Verrier, M., Cherry, R., and Verrier, R. 2000. Ambient pollution and heart rate variability. Circulation 101:12671273.

Gong, H. Jr., Linn, W. S., Sioutas, C., Terrell, S. L., Clark, K. W., Anderson, K. R., and Terrell, L. L. 2003. Controlled exposures of healthy and asthmatic volunteers to concentrated ambient fine particles in Los Angeles. Inhal. Toxicol. 15:305-325. 
Gordon, T., Nadziejko, C., Schlesinger, R., and Chen, L. C. 1998. Pulmonary and cardiovascular effects of acute exposure to concentrated ambient particulate matter in rats. Toxicol. Lett. 96-97:285288.

Harding, S. E., Jones, S. M., O’Gara, P., del Monte, F., Vescovo, G., and Poole-Wilson, P. A. 1992. Isolated ventricular myocytes from failing and non-failing human heart; the relation of age and clinical status of patients to isoproterenol response. J. Mol. Cell Cardiol. 24:549-564.

Ibald-Mulli, A., Stieber, J., Wichmann, H. E., Koenig, W., and Peters, A. 2001. Effects of air pollution on blood pressure: A populationbased approach. Am. J. Public Health 91:571-577.

Kang, Y. J., Li, Y., Zhou, Z., Roberts, A. M., Cai, L., Myers, S. R., Wang, L., and Schuschke, D. A. 2002. Elevation of serum endothelins and cardiotoxicity induced by particulate matter $(\mathrm{PM}(2.5))$ in rats with acute myocardial infarction. Cardiovasc. Toxicol. 2:253262.

Kawano, H., Okada, R., and Yano, K. 2003. Histological study on the distribution of autonomic nerves in the human heart. Heart Vessels 18:32-39.

Kent, K. M., and Cooper, T. 1975. Cardiovascular reflexes. Circulation 52:177-178.

Kiriazis, H., and Gibbs, C. L. 2001. Effects of ageing on the activation metabolism of rat papillary muscles. Clin. Exp. Pharmacol Physiol. 28:176-183.

Kodavanti, U. P., Coata, D. L., and Bromberg, P. A. 1998. Rodent model of cardiopulmonary disease: Their potential applicability in studies of air pollutant susceptibility. Environ. Health Perspect. 106(suppl. 1):111-130.

Kodavanti, U. P., Schladweiler, M. C., Ledbetter, A. D., Watkinson, W. P., Campen, M. J., Winsett, D. W., Richards, J. R., Crissman, K. M., Hatch, G. E., and Costa, D. L. 2000. The spontaneously hypertensive rat as a model of human cardiovascular disease: Evidence of exacerbated cardiopulmonary injury and oxidative stress from inhaled emission particulate matter. Toxicol. Appl. Pharmacol. 164:250-263.

Lai, C. J., and Kou, Y. R. 1998. Stimulation of vagal pulmonary C fiber by inhaled wood smoke in rats. J. Appl. Physiol. 84:30-36.

Linn, W. S., Gong, H. Jr., Clark, K. W., and Anderson, K. R. 1999. Day-to-day particulate exposures and health changes in Los Angeles area residents with severe lung disease. J. Air Waste Manage. Assoc. 49:108-115.

McKeown, K. P., and Shoukas, A. A. 1998. Chronic isolation of carotid sinus baroreceptor region in conscious normotensive and hypertensive rats. Am. J. Physiol. 275(1 Pt. 2):H322-H329.

Moffitt, J. A., Grippo, A. J., Holmes, P. V., and Johnson, A. K. 2002. Olfactory bulbectomy attenuates cardiovascular sympathoexcitatory reflexes in rats. Am. J. Physiol. Heart Circ. Physiol. 283:H2575H2583.

Muggenburg, B. A., Benson, J. M., Barr, E. B., Kubatko, J., and Tilley, L. P. 2003. Short-term inhalation of particulate transition metals has little effect on the electrocardiograms of dogs having preexisting cardiac abnormalities. Inhal. Toxicol. 15:357371.

Nadziejko, C., Fang, K., Nadziejko, E., Narciso, S. P., Zhong, M., and Chen, L. C. 2002. Immediate effects of particulate air pollutants on heart rate and respiratory rate in hypertensive rats. Cardiovasc. Toxicol. 2:245-252.
Nightingale, J. A., Maggs, R., Cullinan, P., Donnelly, L. E., Rogers, D. F., Kinnersley, R., Fan, Chung, K., Barnes, P. J., Ashmore, M., and Newman-Taylor, A. 2000. Airway inflammation after controlled exposure to diesel exhaust particulates. Am. J. Respir. Crit. Care Med. 162:161-166.

Okamoto, K., Yamori, A., and Nagaoka, A. 1974. Establishment of the stroke-prone spontaneously hypertensive rat (SHR). Circ. Res. 34-35:143-153.

Peters, A., Perz, S., Doring, A., Stieber, J., Koenig, W., and Wichmann, H. E. 1999. Increases in heart rate during an air pollution episode. Am. J. Epidemiol. 150:1094-1098.

Peters, A., Liu, E., Verrier, R. L., Schwartz, J., Gold, D. R., Mittleman, M., Baliff, J., Oh, J. A., Allen, G., Monahan, K., and Dockery, D. W. 2000. Air pollution and incidence of cardiac arrhythmia. Epidemiology. 11(1):11-17.

Poller, U., Nedelka, G., Radke, J., Ponicke, K., and Brodde, O. E. 1997. Age-dependent changes in cardiac muscarinic receptor function in healthy volunteers. J. Am. Coll. Cardiol. 29:187-193.

Pope, C. A. III, and Dockery, D. W. 1999. Epidemiology of particle effects. In Air pollution and health eds. S. T., Holgate, J.M., Samet, H. S., Koren, and R. L., Maynard, pp. 673-705. London: Academic Press.

Pope, C. A., Thun, M. J., Namboodiri, M. M., Dockery, D. W., Evans, J. S., Speizer, F. E., and Heath, C. W. 1995. Particulate air pollution as a predictor of mortality in a prospective study of U.S. adults. Am. J. Respir. Crit. Care Med. 151:669-674.

Pope, C. A., Dockery, D. W., Kanner, R. E., Villegas, G. M., and Schwartz, J. 1999. Daily changes in oxygen saturation and pulse rate associated with particulate air pollution and barometric pressure. Am. J. Respir. Crit. Care Med. 159:365-372.

Ren, J., Smude, B. W., Pavlik, M. L., and Brown, R. A. 2000. Diminished cardiac contractile response to tetrahydropapaveroline in hypertension: Role of beta-adrenoceptors and intracellular $\mathrm{Ca}(2+)$. Alcohol 21:149-159.

Robleto, D. O., and Peterson, D. F. 1981. Reduction in cardiac contractility during upper respiratory stimulation with cigarette smoke. Am. J. Physiol. 240:H584-H589.

Ruffolo, R. R. Jr., and Feuerstein, G. Z. 1997. Related pharmacology of carvedilol: Rationale for use in hypertension, coronary artery disease, and congestive heart failure. Cardiovasc. Drugs Ther. 11(suppl. 1):247-256.

Samet, J. M., Dominici, F., Curriero, F. C., Coursac, I., and Zeger, S. L. 2000. Fine particulate air pollution and mortality in 20 U.S. cities, 1987-1994. N. Engl. J. Med. 343:1742-1749.

Sato, M. A., Colombari, E., and Morrison, S. F. 2002. Inhibition of neurons in commissural nucleus of solitary tract reduces sympathetic nerve activity in SHR. Am. J. Physiol. Heart Circ. Physiol. 282:H1679-H1684.

Sioutas, C., Kim, S., and Chang, M. 1999. Development and evaluation of a prototype ultra-fine particle concentrator. J. Aerosol Med. 30:1001-1007.

Stone, P. H., and Godleski, J. J. 1999. First steps toward understanding the pathophysiologic link between air pollution and cardiac mortality. Am. Heart J. 138(5 pt. 1):804-807.

Takahara, A., Dohmoto, H., Yoshimoto, R., Sugiyama, A., Hashimoto, K. 2001. Cardiovascular action of a cardioselective $\mathrm{Ca}(2+)$ channel blocker AH-1058 in conscious dogs assessed by telemetry. Eur. J. Pharmacol. 413:101-108. 
Tibby, S. M., and Murdoch, I. A. 2003. Monitoring cardiac function in intensive care. Arch. Dis. Child. 88:46-52.

Toda, N., Tsukue, N., Tsubone, H., Sagai, M., Birumachi, J., and Suzuki, A. K. 2001. Effects of diesel exhaust particles on blood pressure in rats. J. Toxicol. Environ. Health A 63:429-435.

van Rugge, F. P., van der Wall, E. E., and Bruschke, A. V. 1992. New developments in pharmacologic stress imaging. Am. Heart J. 124:468-485.

Vincent, R., Kumarathasan, P., Goegan, P., Bjarnason, S. G., Guenette, J., Berube, D., Adamson, I. Y., Desjardins, S., Burnett, R. T., Miller, F. J., and Battistini, B. 2001. Inhalation toxicology of urban ambient particulate matter: Acute cardiovascular effects in rats. Res. Rep. Health Effects Inst. 104:5-54.

Watkinson, W. P., Campen, M. J., and Costa, D. L. 1998. Cardiac arrhythmia induction after exposure to residual oil fly ash particles in a rodent model of pulmonary hypertension. Toxicol. Sci. 41(2):209216.
Watkinson, W. P., Campen, M. J., Nolan, J. P., and Costa, D. L. 2001. Cardiovascular and systemic responses to inhaled pollutants in rodents: Effects of ozone and particulate matter. Environ. Health Perspect. 109(suppl. 4):539-546.

Watkinson, W. P., Campen, M. J., Wichers, L. B., Nolan, J. P., and Costa, D. L. 2003. Cardiac and thermoregulatory responses to inhaled pollutants in healthy and compromised rodents: Modulation via interaction with environmental factors. Environ. Res. 92(1):3547.

Wellenius, G. A., Coull, B. A., Godleski, J. J., Koutrakis, P., Okabe, K., Savage, S. T., Lawrence, J. E., Murthy, G. G, and Verrier, R. L. 2003. Inhalation of concentrated ambient air particles exacerbates myocardial ischemia in conscious dogs. Environ. Health Perspect. 111:402-408.

Widdicombe, J., and Lee, L. Y. 2001. Airway reflexes, autonomic function, and cardiovascular responses. Environ. Health Perspect. 109(suppl. 4):579-584. 
Copyright of Inhalation Toxicology is the property of Taylor \& Francis Ltd and its content may not be copied or emailed to multiple sites or posted to a listserv without the copyright holder's express written permission. However, users may print, download, or email articles for individual use. 